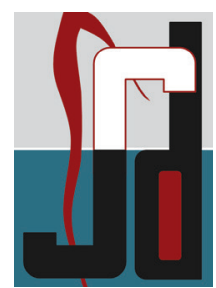

CASE SERIES

\title{
Nonvital tooth- a clue for diagnosis of Radicular cyst- a case report and Review
}

Karthik.R ${ }^{1}$, Mohan. $\mathrm{N}^{2}$

ABSTRACT : Radicular cyst is the most common odontogenic cyst of the Jaws and are accidentally discovered on routine radiographic examination. Radicular cyst cause pain only when infected

Keywords: Periapicalcyst,Prostaglandins, Osteoclast resorbing factors, Interleukins, Rushton Bodies

\section{Introduction}

A 21 Year old Male Patient came to our Department of Oral Medicine,Diagnosis and Radiology Vinayaka Missions sankarachariyar Dental college with a Chief complaint of Pain in the discoloured Lower front tooth region for the Past 1 month.History reveals trauma to his lower front tooth region 6 years back while playing foot ball following which the tooth got discoloured gradually in the lower front tooth region.At present pain started in the discoloured lower front toothwhich is chronic in onset,dull,intermittent,non-radiating in nature in the discoloured lower front tooth region and so he came to our Out Patient Department, Vinayaka Missions sankarachariyar Dental college for treatment. OnExtraoral Examination a single Palpable Submental lymph node present which is tender,mobile,firm in consistency.On Intraoral Examination Discoloured crown seen in relation to 32.Slightly increased interdental spacing seen in between 31,32 tooth region

IOPA(Intraoral Periapical Radiograph) taken in relation to 32 reveals a well defined radiolucency greater than $1.5 \mathrm{~cm}$ in diameter bordered by a radiopaque sclerotic border in relation to 12 suggestive of a Radicular cyst(Periapical or Root-end cyst) in relation to 32.

Treatment Done : Under Local anesthesia (2\% Lignocaine infiltration) a releasing incision done in relation to attached gingiva closer to Mandibular labial vestibule using Bard Parker B.P no :15 and the cystic lining is curetted followed by Endodontic (Root canal )Treatment in relation to discoloured teeth 32.Postoperatively Antibiotic Tab.CLINATEC (200mg Clindamycin) given twice daily for 5 days and a Non-steroidal AntiinflammatoryAnalgesicTab. KETOROL(20 mg Ketorol) prescribed twice daily for 3 days. Pain subsided in the discoloured left mandibular lateral incisor tooth 32.Healing appears satisfactory.

\section{Discussion:}

Radicular cyst (Root end cyst)(Periapical cyst) is the most common odontogenic cyst occurring about 58$62 \%$ in the Human Jaws1.The Radicular (periapical) cyst is usually initiated by Dental caries or Trauma or Periodontally diseased tooth which causes the necrosis (death ) of the Pulp tissue.This necrotic pulp stimulates the rests of malassez 3 within the Periodontal Ligament that results in the formation of epithelial lining in a Radicular cyst.Radicular cyst ( Periapical cyst or Rootend cyst) develops from a pre-existing Periapical granuloma, which is a focus of chronically inflamed granulation tissue formed in bone due to the presence of chronic low grade inflammation located at the apex of a non-vital tooth.The cells of central portion of mass become separated further and further from nutrition in comparison with basal layer due to which they fail to obtain sufficient nutrition, they eventually degenerate, become necrotic and liquify. This creates an epithelium lined cavity filled with fluid.3

Breakdown of cellular debris, Presence of Hyaluronic acid within the cystic lumen raises its protein concentration causing an increase in osmotic pressure inside the cystic lumen which results in fluid transport into the cystic lumen, which causes outward growth of the cyst.4In $10 \%$ of Radicular cyst, hyaline bodies called Rushton Bodies occur in the Epithelial Lining. The cystic fluid of Radicular cyst is usually straw 
coloured or brown due to the presence of blood and when cholesterol crystals are present in the cystic fluid ,they impart an initial shimmering gold appearance when a fresh aspirated cystic fluid is placed on a cotton gauze and seen under a bright light. 1

With osteoclastic bone resorbing factors,resorption of the surrounding alveolar bone occurs and the cyst expands.Other bone resorbing factors such as Prostaglandins,Interleukins from inflammatory cells in the peripheral portion of the cyst permit additional enlargement of Radicular cyst. 2

Radicular cyst is common in the third to sixth decade. Most Radicular cysts are located in the anterior maxillary region.Radicular (root-end or Periapical cyst) is usually Painless and asymptomatic but becomes Painful when infected and are often discovered accidentally during routine dental Radiographic examination.Untreated large Periapical cyst can cause external root resorption of involved tooth and Pathological migration of tooth and expansion of the cortical plate.In Maxillary Jaw, Radicular cyst may cause buccal and palatal cortical plate expansion Whereas in mandible it is usually causes labial or buccal cortical plate expansion and only rarely lingualcortical plate expansion.

A similar case report is reviewed by Karthik $\mathrm{R}$ et al (2016)in which a Radicular cyst associated with a decayed discoloured broken Maxillary rightLateral incisor teeth. 8

Recent evidence suggests that the development of Periapical cyst are mediated by immunocompetent cells in the cystic fluid of Periapical cyst5 and the discontinuity in the epithelial linings of most Periapical cysts.6Activated epithelial cell rests of Malassez can obtain antigenicity or become recognized as antigens and consequently elicit Immunological reactions.7

\section{INTRAORAL CLINICAL PHOTOGRAPH}

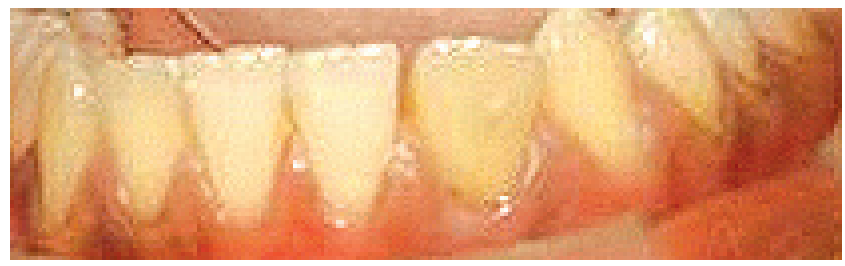

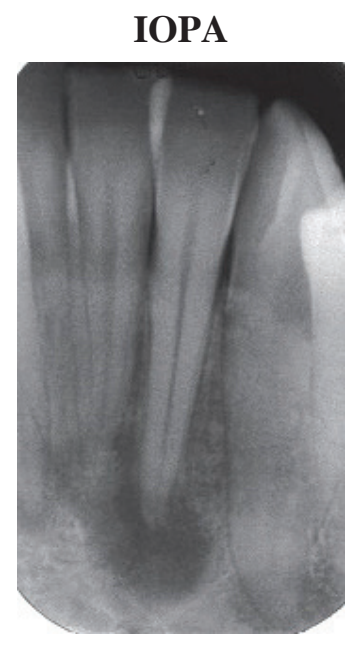

EXCISED RADICULAR CYST

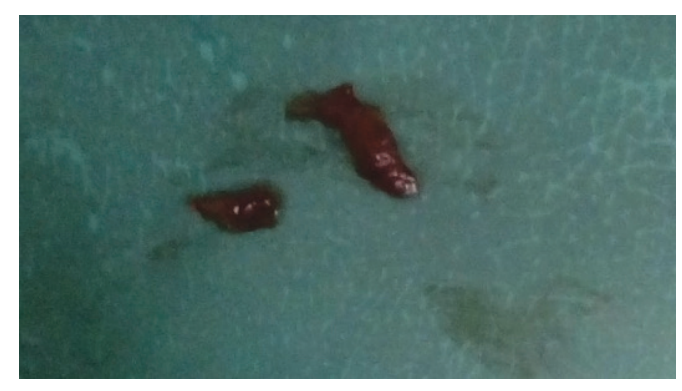

ROOT CANAL TREATMENT DONE IN 32

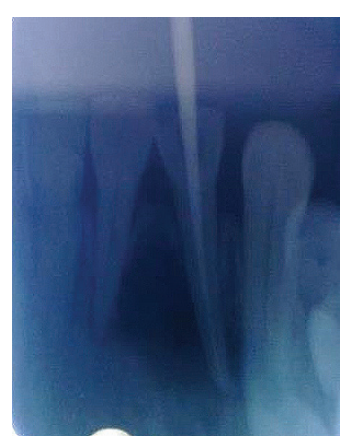
CROWN PREPARATION DONE IN
DISCOLOURED TEETH 32

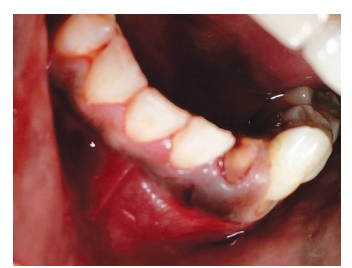

CERAMIC CROWN CEMENTED IN 32

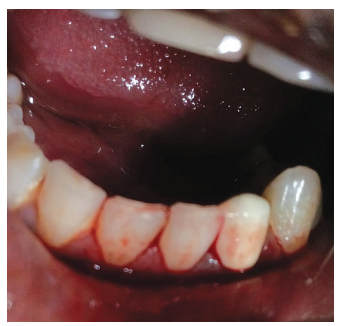

Journal of Scientific Dentistry, 6(2), 2016 


\section{References :}

1. Shear M. Cysts of the oral regions. 3rd ed. Boston: Wright; 1992. Radicular and residual cysts; pp. 136-62.

2. Bonder L. Cystic lesions of the jaws in children. Int $\mathbf{J}$ PediatOtorhinolaryngol. 2002;62:25-9

3. Ten Cate AR. The epithelial cell rests of Malassez and the genesis of the dental cyst. Oral Surg Oral Med Oral Pathol. 1972;34:956-64.

4. Main DM. Epithelial jaw cysts: 10 years of the WHO classification. J Oral Pathol. 1985;14:1-7.

5. TollerPA, HolborrowEJ. Immunoglobulins and Immunoglobulin containing cells in cysts of the jaws.Lancet 1969;2:178.

\section{Address of Correspondence}

Karthik R.

Reader,

Department of oral Medicine and Radiology

Vinayaka Missions Sankarachariyar Dental College,

Salem.
6. TollerPA,Epithelial discontinuities in cysts of the Jaws. British Dental Journal 1966;120:74.

7. TorabinejadM.The role of immunological reactions in apical cyst formation and the fate of epithelium after root canal treatment: a theory,International journal of oral surgery, 1983;12:14.

8. Karthik.R,Mohan N, RavikumarPT,Sabitha,CiciliaSubb ulakshmi,Saramma Mathew Fenn,Radicular cyst- a case report,IJREAS,Jan 2016,Vol 6,Issue 1.

\section{Authors:}

${ }^{1}$ Reader,Department of oral Medicine and Radiology,Vinayaka Missions sankarachariyar Dental college, Salem

${ }^{2}$ Professor and Head of Department,Department of oral Medicine and Radiology,Vinayaka Missions Sankarachariyar Dental college, Salem.

\section{How to cite this article :}

Karthik .R, Mohan .N. Nonvital tooth- a clue for diagnosis of Radicular cyst- a case report and Review. Journal of Scientific Dentistry, 2016;6(2):50-52

Source of Support : Nil, Conflicts of Interest : None declared 